\title{
The combinatorial use of propofol-fentanyl-ketamine for sedoanalgesia in patients undergoing urological procedures
}

\author{
Abdelkarim S. Aloweidi, MD, FACHARZT, Sami A. Abu-Halaweh, MD, FFARCSI, Ghazi M. Al-Edwan, MD, \\ Saddam H. AL Demour, MD, Laith T. Abu Mahfuz, MD, Osama N. Noubani, MD, Mohammad M. Al Rwaidi, MD, \\ Isam K. Bsisu, MD, Mohammad M. Abufaraj, MD.
}

\begin{abstract}

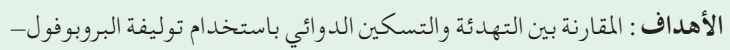

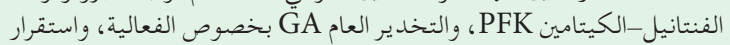

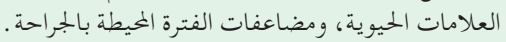

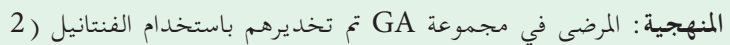

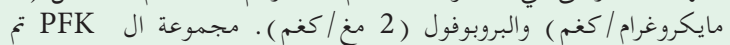

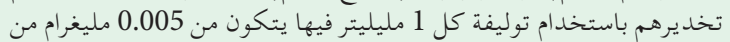

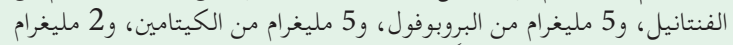

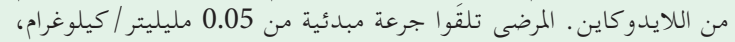

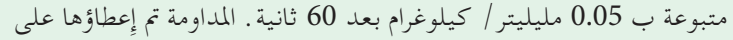

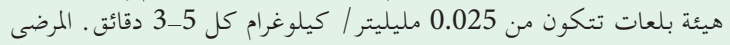

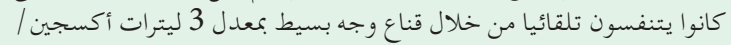
دقيقة.

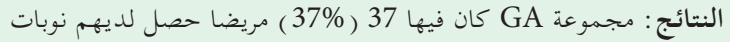

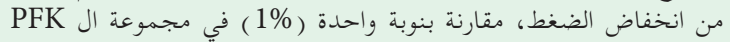
نوبة

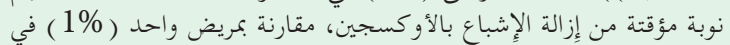

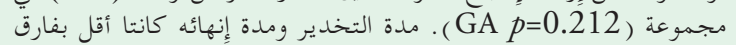
واضح في مجموعة ( PFK،

الحخلاصة: توليفة (PFK) آمنة، وفعالة وتوفر استقراراً بالعلامات الحيوية

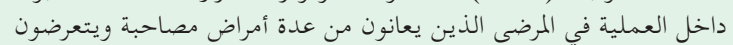

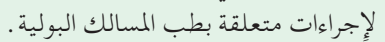

Objectives: To compare sedoanalgesia achieved using propofol-fentanyl-ketamine (PFK) combination with general anesthesia (GA) in terms of safety, hemodynamic stability, and perioperative complications.

Methods: Patients in the GA group were anesthetized using fentanyl $\left(2 \mu \mathrm{g} \mathrm{kg}^{-1}\right)$ and propofol $\left(2 \mathrm{mg} \mathrm{kg}^{-1}\right)$. The PFK group was anesthetized using a mixture of which each one $\mathrm{ml}$ contains $0.005 \mathrm{mg}$ of fentanyl, $5 \mathrm{mg}$ of propofol, $5 \mathrm{mg}$ of ketamine, and $2 \mathrm{mg}$ of lidocaine. Patients received an initial dose of $0.05 \mathrm{ml} \mathrm{kg}^{-1}$, followed by $0.05 \mathrm{mg} \mathrm{kg}^{-1} 60$ seconds later. Maintenance boluses of $0.025 \mathrm{ml} \mathrm{kg}^{-1}$ were administered every 3-5 minutes. Respiration occurred spontaneously through a simple face mask with $3 \mathrm{~L} \mathrm{~min}^{-1} \mathrm{O}_{2}$.

Results: The GA group had 37 (37\%) patients develop hypotensive episodes, compared to one $(1 \%)$ episode in the PFK group $(p<0.001)$. Five $(5 \%)$ patients in the PFK group had an episode of transient $\mathrm{O}_{2}$ desaturation, compared to one (1\%) patient in the GA group $(p=0.212)$. The duration of induction and termination of anesthesia were significantly shorter in the PFK group $(p<0.001)$.

Conclusion: The PFK combination herein described is safe, effective, and provides intraoperative hemodynamic stability in patients with multiple comorbidities undergoing urological procedures.

Keywords: propofol, fentanyl, ketamine, general anesthesia, urological procedures

Saudi Med J 2021; Vol. 42 (6): 629-635 doi: 10.15537/smj.2021.42.6.20210071

From the Department of Anesthesia and Intensive Care (Aloweidi, Abu-Halaweh, Abu Mahfuz, Noubani, Al Rwaidi, Bsisu); from the Division of Urology, Department of Special Surgery (Al-Edwan, AL Demour, Abufaraj), School of Medicine, The University of Jordan, Amman, Jordan; and from the Department of Urology (Abufaraj), Medical University of Vienna, Vienna, Austria.

Received 6th February 2021. Accepted 18th April 2021.

Address correspondence and reprint request to: Dr. Isam $K$. Bsisu, Department of Anesthesia and Intensive Care, School of Medicine, The University of Jordan, Amman, Jordan. E-mail:Isam_Bsisu@hotmail.com ORCID ID: https://orcid.org/0000-0002-8999-8334 
U rological procedures constitute a big challenge for anesthesiologists, whose role is to ensure that patients with coexisting medical conditions are optimally managed before, during, and after surgery. ${ }^{1}$ Propofol is a hypnotic sedative with a rapid onset and short duration of action, leading to the rapid recovery of cognitive and psychomotor functions. On the other hand, ketamine is used as an amnestic and dissociative analgesic agent. ${ }^{2}$ The use of ketamine and propofol together at a 1:1 ratio in a single syringe has been widely used as a chemically and physically stable mixture to provide procedural sedation and analgesia for different surgical procedures. ${ }^{3}$ Their combination, known as ketofol confers higher sedation quality and higher satisfaction rates among both physicians and nurses. ${ }^{4}$ Furthermore, ketofol is significantly more effective in reducing respiratory and cardiovascular complications, including hypotension and bradycardia, than propofol alone. ${ }^{5}$ Pain management is a significant part of the perioperative patient experience in urological interventions. ${ }^{6}$ Fentanyl is an effective opioid analgesic that is one hundred times more potent than morphine, rendering it well suited for the management of a short duration of intense pain. ${ }^{7}$ Upon comparing the combination of propofol and fentanyl with ketofol, both combinations provided effective sedation, but ketofol resulted in more profound sedation and stable hemodynamics, though it had more side effects. ${ }^{8,9}$

The combination of propofol, fentanyl, and ketamine (PFK) for sedoanalgesia has not been thoroughly investigated. ${ }^{10,11}$ A previous study conducted on only 21 patients undergoing extracorporeal shock-wave lithotripsy (ESWL) concluded that highloading dose and low-demand boluses of PFK is the most appropriate for patient-controlled sedation and analgesia during ESWL. ${ }^{12}$ The aforementioned study compared 3 methods of PFK administration with 7 patients per group. However, the authors did not compare PFK with general anesthesia (GA) in terms of efficacy, hemodynamic stability, and postoperative complications. Thus, we aimed to compare the PFK combination with GA in terms of the incidence of intraoperative hypotension. In addition to sedative efficacy, perioperative adverse events, and postoperative satisfaction rates.

Disclosure. Authors have no conflict of interests, and the work was not supported or funded by any drug company.
Methods. This open-label, quasi-experimental study was conducted at Jordan University Hospital (JUH), Amman, Jordan between June 2018 and June 2019, during which 201 patients were enrolled. We included patients older than 30 years with American Society of Anesthesiologists (ASA) physical status classification of 2 and above who underwent cystoscopy, ureteroscopy, double J stent insertion or removal, and transrectal ultrasound-guided (TRUS) biopsy. The study protocol was approved by the Institutional Review Board at JUH, Amman, Jordan (No. 67/2019/1166). The study was reported in accordance with the STROBE statement (https://www.strobe-statement.org/).

Patients were divided into 2 groups: the PFK sedoanalgesia group (PFK group) and the GA group. The method of anesthetic technique delivered was based on the patient's choice between the 2 aforementioned methods. None of the included patients were found to be eligible, declined to participate, or withdrew from the study. A post-hoc power analysis performed after patient recruitment assuming a type I error of 0.05 showed that the current sample size corresponded to a $>95 \%$ power rate.

Anesthetic techniques. The patients were evaluated during pre-operative assessment rounds, during which their age and gender were recorded. Moreover, we documented their chronic medical conditions, smoking habits, regular medications, cardiac and respiratory health, complete blood count, and kidney function tests. In addition, we reviewed patients' electrocardiogram (ECG), chest $\mathrm{x}$-rays, vital signs, $\mathrm{O}_{2}$ saturation at room air, and their weight in kilograms. Written informed consent was obtained from all patients for the upcoming anesthetic and urological procedures, as well as for their enrolment in the study and further follow-up.

In the operating room, patients' vital signs before induction, including their heart rate, pulse oximeter for oxygen saturation, non-invasive systolic blood pressure, diastolic blood pressure, and mean blood pressure were monitored. Before delivering the anesthetic agents intravenously, the ECG was monitored for all patients, intravenous access was established using a 20-gauge cannula, and pre-oxygenation was performed for 3 minutes at $100 \% \mathrm{O}_{2}$.

Patients in the GA group were anesthetized with fentanyl $(2 \mu \mathrm{g}$ per $\mathrm{kg}$ ) and propofol $(2 \mathrm{mg}$ per $\mathrm{kg})$. A classic, proper (weight-based) laryngeal mask airway (LMA) was then inserted, and anesthesia was maintained using one minimum alveolar concentration) of end-tidal inhalational isoflurane. Those in the PFK group were anesthetized using a mixture of fentanyl, propofol, ketamine, and lidocaine in a single syringe. ${ }^{13}$ 
The mixture consisted of $0.1 \mathrm{mg}$ of fentanyl, $100 \mathrm{mg}$ of $1 \%$ propofol, and $100 \mathrm{mg}$ of ketamine mixed in a single syringe just prior to their administration. In addition, $40 \mathrm{mg}$ of $2 \%$ lidocaine was added in order to reduce the pain on injection caused by propofol. ${ }^{14}$ Moreover, $4 \mathrm{ml}$ of distilled water were added to the mixture in one $20-\mathrm{ml}$ syringe. This will result in a mixture of $0.005 \mathrm{mg} \mathrm{ml}^{-1}$ of fentanyl, $5 \mathrm{mg} \mathrm{ml}^{-1}$ of propofol, $5 \mathrm{mg} \mathrm{ml}^{-1}$ of ketamine, and $2 \mathrm{mg} \mathrm{ml}^{-1}$ lidocaine. For convenience and simplicity, the initial and maintenance doses are presented in $\mathrm{ml} \mathrm{kg}{ }^{-1}$ throughout the entire manuscript. Each patient received an initial dose of $0.05 \mathrm{ml} \mathrm{kg}^{-1}$ from the solution and, after 60 seconds, another $0.05 \mathrm{ml} \mathrm{kg}^{-1}$ dose was delivered. Both groups were provided maintenance boluses of no more than $0.025 \mathrm{ml} \mathrm{kg}^{-1}$ every 3-5 minutes. No LMA or endotracheal tube was inserted, and all patients were breathing spontaneously through a simple face mask with $3 \mathrm{~L} \mathrm{~min}^{-1} \mathrm{O}_{2}$.

Intra-operatively, changes in vital signs including heart rate and rhythm, blood pressure, respiratory rate, oxygen saturation, end-tidal $\mathrm{CO}_{2}$, bispectral index scores (BIS), and skin temperature were recorded. A significant change in systolic blood pressure was defined as a $20 \%$ decrease from baseline, ${ }^{15}$ while $\mathrm{O}_{2}$ desaturation was defined as a decrease in $\mathrm{O}_{2}$ below $90 \%$ measured using a pulse oximeter. ${ }^{16}$ In the case of an absence of end-tidal $\mathrm{CO}_{2}$ readings via a capnogram or $\mathrm{O}_{2}$ desaturation, airway manipulations (such as, jaw thrust, chin lift, head tilt) were performed, and an airway was inserted orally when necessary. Furthermore, we documented all medications provided intra-operatively, including vasopressors (ephedrine), the duration of the surgery, the duration of anesthesia induction, and the duration of anesthesia termination.

After the termination of anesthesia, the patient was transferred to the post-anesthesia care unit (PACU), where we recorded the incidence of nausea or vomiting, postoperative hallucinations, and respiratory depression as well as the time needed to regain full consciousness, alertness, and orientation, which were assessed by asking patients regarding their name, current location, and date. Patients were asked if they remembered any intraoperative events. For example, whether they remember when their legs were raised into a lithotomy position or when the cystoscope was inserted. Moreover, we used a numerical rating scale (NRS-11) to record pain scores postoperatively, and all pain medications administered while in the PACU were also recorded. Finally, we surveyed the patients' and surgeons' satisfaction with the chosen anesthesia modality 24 hours postoperatively using a 5-point scale, where 5 stands for "completely satisfied," and one stands for "not satisfied at all". ${ }^{17}$
Statistical analysis. The Statistical Package for Social Sciences, version 21.0 (IBMCorp, Armonk, NY, USA) was used to analyze the data. The median (interquartile range $[\mathrm{IQR}]$ ) was used to describe age, weight, duration of induction, duration of the procedure, duration of termination, the time needed to regain full consciousness, pain score, and satisfaction scores. A numerical count (percent) was used to describe the categorical variables.

The Mann-Whitney $U$ test was used to analyze the median difference between the 2 groups in age, weight, induction duration, procedure duration, termination duration, the time needed to regain full consciousness, pain score, and satisfaction scores. Chi-squared $\left(\chi^{2}\right)$ and Fisher's exact tests were used to investigate the presence of significant differences between the 2 independent groups in gender, smoking habits, comorbidities, episodes of intraoperative hypotension, use of vasopressors, intraoperative transient hypoxia, intraoperative penile erection, postoperative complications, and the need for postoperative analgesia. Univariable logistic regression analysis was performed to predict factors associated with hypotension in our cohort, and we included variables that were significant in the univariable model in the multivariable logistic regression analysis. Moreover, we ran a model with the type of urological procedures, which did not change the results of the previous regression models. A 2-sided p-value $<0.05$ was used as the significance threshold.

Results. A total of 201 patients were included, of which 100 were assigned to the GA group, while 101 were enrolled in the PFK group. The median age was 52 years (IQR: 42-65.5). Of the 201 patients, 161 (80.1\%) were male, while 40 (19.9\%) were female. Demographic data, smoking habits, and chronic medical illnesses are shown in Table 1. No significant differences were found between the 2 study groups in terms of demographic data or pre-operative medical status.

Upon comparing the 2 groups in the perioperative period, a significant difference was found between them in terms of duration of induction, duration of surgery, and duration of anesthesia termination $(p<0.001)$. In the PFK group, the median duration of induction was 2 [2-4] minutes, the median duration of surgery was 15 [15-25] minutes, and the median duration of termination was 1 [0-3] minute. The mean duration of induction, duration of surgery, and duration of termination were 5 [4-7] minutes, 30 [15.25-40] minutes, and 7 [5-9.75] minutes, respectively for the GA group (Table 2). Upon investigating the BIS for patients in the PFK group, we found that the median 
Propofol-fentanyl-ketamine combination for sedoanalgesia ... Aloweidi et al

Table 1 - A comparison between the 2 groups in terms of patients' demographics.

\begin{tabular}{|c|c|c|c|}
\hline Characteristics & $\underset{(n=100)}{\text { GA }}$ & $\begin{array}{c}\text { PFK } \\
(\mathrm{n}=101)\end{array}$ & $P$-value \\
\hline Age, years [IQR] & $51[41.3-66.8]$ & $53[42.5-64]$ & 0.758 \\
\hline \multicolumn{4}{|l|}{ Gender } \\
\hline Male & $80(80)$ & $81(80.2)$ & \multirow{2}{*}{0.972} \\
\hline Female & $20(20)$ & $20(19.8)$ & \\
\hline \multicolumn{4}{|l|}{ Smoking } \\
\hline Smoker & $55(55)$ & $45(44.5)$ & \multirow{3}{*}{0.263} \\
\hline Non-smoker & $4(4)$ & $3(3.0)$ & \\
\hline Ex-smoker & $41(41)$ & $53(52.5)$ & \\
\hline Weight, kilograms [IQR] & $81[73-90]$ & $80[70-90]$ & 0.663 \\
\hline Hypertension, & $33(33)$ & $40(39.6)$ & 0.33 \\
\hline Diabetes mellitus & $22(22)$ & $26(25.7)$ & 0.534 \\
\hline Iischemic heart disease & $8(8)$ & $11(10.9)$ & 0.484 \\
\hline Chronic kidney disease & $10(10)$ & $6(5.9)$ & 0.288 \\
\hline \multicolumn{4}{|c|}{$\begin{array}{l}\text { Values are presented as numbers and percentages (\%). Mann-Whitney } \mathrm{U} \text { test, Chi-squared tes } \\
\left(\chi^{2} \text { test }\right) \text {, and Fisher's exact test were used to investigate the presence of significant difference } \\
\text { between the } 2 \text { independent groups. GA: general anaesthesia, IQR: interquartile range, } \\
\text { PFK: propofol-fentanyl-ketamine }\end{array}$} \\
\hline
\end{tabular}

score for the minimum BIS readings was 71 [68-76], compared with a median score of 79 [74-84] for the maximum BIS readings.

The GA group had significantly more patients with hypotension $(p<0.001)$, with $37(37 \%)$ of patients in this group suffering from hypotension. In contrast, only one $(1 \%)$ episode of hypotension occurred in the PFK group. Thus, $97.4 \%$ of episodes of hypotension in this study were in the GA group. Vasopressor use followed the same trend $(p<0.001)$, with $30(30 \%)$ patients in the GA group needing vasopressors, while none of those in the PFK group required vasopressor mediation. On multivariable analysis, age (odd ratio [OR]: 1.05; 95\% confidence interval [CI]: 1.02 to $1.08 ; p=0.004)$, and GA (OR: 65.78 ; 95\% CI: 8.17 to 529.5 ; $p<0.001$ ) were independently associated with hypotension (Table 3 ).

Upon evaluating post-induction transient $\mathrm{O}_{2}$ desaturation, $5(5 \%)$ patients in the PFK group had an episode of transient $\mathrm{O}_{2}$ desaturation, compared to only one (1\%) patient in the GA group $(p=0.212)$. Furthermore, airway management was more often required for the PFK group ( $p<0.001)$, with 25 (24.8\%) needing airway manipulation, of which 15 (14.9\%) were resolved by jaw thrust, 4 (4\%) chin lift, 2 (2\%) head tilt or head repositioning, and $3(3 \%)$ necessitated airway insertion.

There were no significant differences between the 2 groups in postoperative complications, pain scores, or the need for analgesia $(p>0.05)$ (Table 1$)$. However, the patients' satisfaction scores were significantly lower among the PFK group $(p<0.001)$ with a median score of $3(3-4)$ compared with a median score of 5 (4-5) in the GA group.

Discussion. In this study, we compared intravenous anesthesia using PFK and lidocaine with GA using fentanyl, propofol, and inhalational isoflurane for maintenance. This study investigated the use of PFK together for urological procedures in patients from Arab descent.

Several studies have investigated the efficacy of the PFK combination, but using different methods of administration. ${ }^{12,18-20}$ In a study investigating the use of PFK mixed in a single syringe for patients undergoing ESWL, Tokumine et $\mathrm{al}^{12}$ included 3 groups, with only 7 patients per group. The drug administration differences between these groups included the loading dose and additional self-administration. The propofol loading dose was either 0.25 or $0.35 \mathrm{mg} \mathrm{kg}^{-1}$ and the additional self-administered dose was either 0.25 or $0.20 \mathrm{mg} \mathrm{kg}^{-1}$. The maintenance dose and lockout interval (3 minutes) were the same in the 3 groups. As such, the 3 groups were divided pharmacologically into: group 1, low loading dose and high demand bolus; group 2, high loading dose and high demand bolus; and group 3, high loading dose and low demand bolus. Of these, the PFK combination received by group 3 was the most appropriate for patient-controlled sedation and analgesia during ESWL. ${ }^{12}$ In the current study, the single PFK syringe contained $0.005 \mathrm{mg} \mathrm{ml}^{-1}$ of fentanyl, $5 \mathrm{mg} \mathrm{ml}^{-1}$ of propofol, $5 \mathrm{mg} \mathrm{ml}^{-1}$ of ketamine, and $2 \mathrm{mg} \mathrm{ml}-1$ of lidocaine. The loading dose for each patient 
Table 2 - A comparison between the two groups in terms of intraoperative adverse events, post-operative complications, operative duration, and patients' satisfaction.

\begin{tabular}{|c|c|c|c|}
\hline Characteristics & $\underset{(n=100)}{\text { GA }}$ & $\begin{array}{c}\text { PFK } \\
(\mathrm{n}=101)\end{array}$ & $P$-value \\
\hline Duration of induction, minutes [IQR] & $5[4-7]$ & $2[2-4]$ & $<0.001$ \\
\hline Duration of surgery, minutes [IQR] & $30[15.25-40]$ & $15[15-25]$ & $<0.001$ \\
\hline Duration of termination of anaesthesia, minutes [IQR] & $7[5-9.75]$ & $1[0-3]$ & $<0.001$ \\
\hline Hypotension & $37(37)$ & $1(1.0)$ & $<0.001$ \\
\hline Use of vasopressor & $30(30)$ & $0(0)$ & $<0.001$ \\
\hline Transient $\mathrm{O}_{2}$ desaturation & $1(1)$ & $6(6.0)$ & 0.212 \\
\hline Airway management required & $3(3)$ & $25(24.8)$ & $<0.001$ \\
\hline Penile erection & $3(3)$ & $1(1.0)$ & 0.369 \\
\hline \multicolumn{4}{|l|}{ Postoperative data } \\
\hline Nausea and vomiting & $2(2)$ & $4(4.0)$ & \multirow{3}{*}{0.374} \\
\hline Nausea without vomiting & $5(5)$ & $2(2.0)$ & \\
\hline Neither nausea nor vomiting & $93(93)$ & $95(94.0)$ & \\
\hline Hallucination & $5(5)$ & $8(7.9)$ & 0.400 \\
\hline Respiratory depression & $3(3)$ & $5(5.0)$ & 0.721 \\
\hline Remembering intraoperative events & $10(10)$ & $15(14.9)$ & 0.297 \\
\hline Pain score, median [IQR] & $1[1-2]$ & $1[1-2]$ & 0.197 \\
\hline Post-operative paracetamol & $18(18)$ & $14(13.9)$ & \multirow{2}{*}{0.597} \\
\hline Post-operative morphine & $1(1)$ & $2(2.0)$ & \\
\hline Median time to regain consciousness, minutes (IQR) & $10[10-20]$ & $15[10-20]$ & 0.322 \\
\hline Liked the experience & $83(83)$ & $74(73.3)$ & 0.095 \\
\hline Satisfaction score, median (IQR) & $5[4-5]$ & $3[3-4]$ & $<0.001$ \\
\hline \multicolumn{4}{|c|}{$\begin{array}{l}\text { Values are presented as numbers and percentages }(\%) \text {. Mann-Whitney } U \text { test, Chi-squared test }(\chi 2 \text { test) and Fisher's } \\
\text { exact test were used to investigate the presence of significant difference between the } 2 \text { independent groups. *GA: } \\
\text { general anaesthesia, IQR interquartile range, PFK: propofol-fentanyl-ketamine, Bold numbers indicate statistically } \\
\text { significant correlations. }\end{array}$} \\
\hline
\end{tabular}

Table 3 - Univariable and multivariable logistic regression for predicting hypotension in our cohort.

\begin{tabular}{lcccccc}
\hline Variable & \multicolumn{3}{c}{ Univariable } & \multicolumn{3}{c}{ Multivariable } \\
& OR & $95 \%$ CI & $P$-value & OR & 95\% CI & $P$-value \\
\hline Age & 1.04 & $1.01-1.06$ & $\mathbf{0 . 0 0 4}$ & 1.05 & $1.02-1.08$ & $\mathbf{0 . 0 0 4}$ \\
gender (ref. male) & 0.42 & $0.14-1.25$ & 0.117 & - & - & - \\
Weight & 1.00 & $0.97-1.02$ & 0.734 & - & - & - \\
Duration of induction & 1.27 & $1.12-1.45$ & $<\mathbf{0 . 0 0 1}$ & 1.05 & $0.91-1.23$ & 0.436 \\
Type of anaesthesia (ref. GA) & 58.73 & $7.86-438.8$ & $<\mathbf{0 . 0 0 1}$ & 65.78 & $8.17-529.5$ & $<\mathbf{0 . 0 0 1}$ \\
\hline
\end{tabular}

Bold numbers indicate statistically significant correlations. GA: general anaesthesia; 95\% CI: 95\% confidence interval,

was $0.05 \mathrm{ml} \mathrm{kg}^{-1}$, followed by another $0.05 \mathrm{ml} \mathrm{kg} \mathrm{kg}^{-1}$ 60 seconds later. Maintenance was provided via boluses of $0.025 \mathrm{ml} \mathrm{kg}^{-1}$ every 3-5 minutes.

Notably, most of these studies used hemodynamic stability as their primary intraoperative indicator of safety and efficacy for this anesthetic regimen. For example, in an investigation of low-dose ketamine with propofol-fentanyl anesthesia during diagnostic gynecological laparoscopy, Atashkhoyi et $\mathrm{al}^{18}$ found that the decrease in mean arterial pressure was greater in the placebo group (37\%) compared with the study group (7\%). In that study, ketamine $\left(0.5 \mathrm{mg} \mathrm{kg}^{-1}\right)$ and propofol (1-2.5 $\mathrm{mg} \mathrm{kg}^{-1}$ ) were administered after the injection of midazolam and fentanyl in all patients. This decrease in the rate of hypotension can be attributed to the sympathomimetic effect of ketamine; ${ }^{21}$ thus, the administration of ketamine alongside propofol can be beneficial in preventing significant decreases in arterial pressure in relation to baseline pre-operative measures thereby reducing fluctuations in hemodynamic variables. ${ }^{19,22,23}$ In a more detailed hemodynamic investigation, Hayakawa-Fuji et $\mathrm{a}^{19}$ used a regimen of 
fentanyl $\left(3 \mu \mathrm{g} \mathrm{kg}^{-1}\right)$ followed by propofol $\left(2 \mathrm{mg} \mathrm{kg}^{-1}\right)$ and ketamine $\left(0.1 \mathrm{mg} \mathrm{kg}^{-1}\right) 60$ seconds later for 15 patients in their PFK group, in which they found that cardiac output, cardiac index, stroke volume, and stroke volume index at a postintubation time-point remained unaffected compared with their pre-intubation levels, concluding that this combination reduced the fluctuations in hemodynamic variables associated with the induction of anesthesia and endotracheal intubation.

Interestingly, previous studies suggest that the use of a PFK combination decreases the risk of $\mathrm{O}_{2}$ desaturation in adult ${ }^{20}$ and pediatric patients, ${ }^{24}$ for which PFK was deemed safe. ${ }^{25,26}$ The contradictory results in the current study can be attributed to the utilization of LMA for patients in the GA group, thereby largely preventing those patients from developing $\mathrm{O}_{2}$ desaturation. On the other hand, in the randomized controlled trial of Tang et al, ${ }^{20} \mathrm{O}_{2}$ was supplemented through a facemask connected to the breathing circuit at $3 \mathrm{~L} \mathrm{~min}^{-1}$, leading to a higher percentage of $\mathrm{O}_{2}$ desaturation in the propofol-fentanyl GA group.

The choice of anesthetic technique is a major contributing factor to the cost-effectiveness of an operating theatre. A recent cross-sectional, longitudinal analysis showed that from 2005 to 2014, the mean cost per minute of operating theatre time across California hospitals was $\$ 37.45$ in the inpatient setting and $\$ 36.14$ in the ambulatory setting. ${ }^{27}$ In this study, the median duration of induction, duration of surgery, and duration of anesthesia termination were all significantly shorter in the PFK group. However, our results contradict those of Kakinohana et $\mathrm{al}^{28}$ where the time to extubation was significantly longer in the PFK group compared with the propofol-fentanyl GA group. This is likely due to the anesthetic technique used by their group of $1.5 \mathrm{mg} \mathrm{kg}^{-1}$ of propofol, $2 \mu \mathrm{g} \mathrm{kg}^{-1}$ of fentanyl, and $1 \mathrm{mg} \mathrm{kg}^{-1}$ of ketamine followed by endotracheal intubation after $0.1 \mathrm{mg} \mathrm{kg}^{-1}$ of vecuronium and a maintenance phase achieved by infusing $5-10 \mathrm{mg} \mathrm{kg}^{-1}$ of propofol and $1 \mathrm{mg} \mathrm{kg}^{-1}$ of ketamine per hour until a dose of $2 \mathrm{mg} \mathrm{kg}^{-1}$ ketamine with no additional fentanyl administration.

Even though there were no significant differences in postoperative pain scores, postoperative analgesics, or intraoperative event recall, the satisfaction scores were significantly lower among patients in the PFK group. On the contrary, several previous studies describe significant decreases in the need for postoperative analgesia and postoperative pain scores. ${ }^{28-30}$ Moreover, the satisfaction rates vary in the literature, with some studies showing that both surgeons' and patients' satisfaction scores were significantly higher with the PFK combination, ${ }^{30}$ while others only reach significance in surgeons' satisfaction. ${ }^{20}$ These contradictory results highlight the need for a formal evaluation of postoperative patient satisfaction using different validated satisfaction rating systems that take into account patients' expectations provided that the gap between expectation and experience from the patient's perspective is likely the predominant factor underlying these controverting results. ${ }^{31}$

Study limitations. The main limitation of this study was the inability to assess the depth of anesthesia at different points throughout the procedure. Even though we did not find a significant difference between the 2 groups in recalling intraoperative events. While the BIS scores were recorded for patients in the PFK group, the protocol for patients undergoing minor surgeries under GA does not include BIS recording at our institution. Thus, we were not able to compare anesthesia depth between the 2 study groups. Previous studies reported difficulties in evaluating the depth of anesthesia using electroencephalography under PKF anesthesia, ${ }^{32,33}$ for which further investigations are warranted. Additionally, surgeons' satisfaction should be thoroughly evaluated in future studies using a validated questionnaire, taking into consideration intraoperative sphincter relaxation, procedure time, and recovery time. Moreover, we recommend future studies on PFK combination include an investigation into the minimum effective doses for induction and maintenance, in order to achieve the desired depth of anesthesia with fewer adverse events, such as transient $\mathrm{O}_{2}$ desaturation.

In conclusion, the combinatorial use of PFK was safe and effective in patients undergoing urological procedures. Intraoperative hemodynamic stability is one of the main factors supporting the use of this PFK combination for patients with multiple comorbidities. Nevertheless, more investigations are needed to reach a consensus on the most effective induction and maintenance doses for other urological and nonurological procedures.

Acknowledgment. We would like to thank American manuscript editors (https://americanmanuscripteditors.com/) for English language editing.

\section{References}

1. White PF, Kehlet H, Neal JM, Schricker T, Carr DB, Carli F, et al. The role of the anesthesiologist in fast-track surgery: from multimodal analgesia to perioperative medical care. Anesth Analg 2007; 104: 1380-1996.

2. Jalili M, Bahreini M, Doosti-Irani A, Masoomi R, Arbab M, Mirfazaelian H. Ketamine-propofol combination (ketofol) vs propofol for procedural sedation and analgesia: systematic review and meta-analysis. Am J Emerg Med 2016; 34: 558-569. 
3. Ferguson I, Bell A, Treston G, New L, Ding M, Holdgate A. Propofol or ketofol for procedural sedation and analgesia in emergency medicine-the POKER study: a randomized doubleblind clinical trial. Ann Emerg Med 2016; 68: 574-582.

4. David H, Shipp J. A randomized controlled trial of ketamine/ propofol versus propofol alone for emergency department procedural sedation. Ann Emerg Med 2011; 57: 435-441.

5. Oh C, Kim Y, Eom H, Youn S, Lee S, Ko YB, Yoo HJ, Chung W, Lim C, Hong B. Procedural sedation using a propofolketamine combination (Ketofol) vs. propofol alone in the loop electrosurgical excision procedure (LEEP): A randomized controlled trial. J Clin Med 2019; 8: 943.

6. Morrison K, Herbst K, Corbett S, Herndon CA. Pain management practice patterns for common pediatric urology procedures. Urology 2014; 83: 206-210.

7. Borland M, Bergesio R, Pascoe E, Turner S, Woodger S. Intranasal fentanyl is an equivalent analgesic to oral morphine in paediatric burns patients for dressing changes: a randomised double blind crossover study. Burns 2005; 31: 831-837.

8. Tosun Z, Aksu R, Guler G, Esmaoglu A, Akin A, Aslan D, et al. Propofol-ketamine vs propofol-fentanyl for sedation during pediatric upper gastrointestinal endoscopy. Paediatr Anaesth 2007; 17: 983-988.

9. Singh Bajwa SJ, Bajwa SK, Kaur J. Comparison of 2 drug combinations in total intravenous anesthesia: Propofolketamine and propofol-fentanyl. Saudi J Anaesth 2010; 4: 72-79.

10. Kushikata T, Yatsu Y, Kubota T, Matsuki A. Total intravenous anesthesia with propofol, ketamine, and fentanyl (PFK) for a patient with mitochondrial myopathy. Masui 2004; 53: 178-180.

11. Kakinohana M, Saitoh T, Kakinohana O, Okuda Y. [A case of total intravenous anesthesia with propofol, fentanyl and ketamine for lateral segmentectomy of the liver under pringle maneuver]. Masui 1999; 48: 523-527.

12. Tokumine J, Iha H, Okuda Y, Shimabukuro T, Shimabukuro $\mathrm{T}$, Ishigaki K, et al. Appropriate method of administration of propofol, fentanyl, and ketamine for patient-controlled sedation and analgesia during extracorporeal shock-wave lithotripsy. $J$ Anesth 2000; 14: 68-72.

13. Bedocs P, Evers DL, Buckenmaier CC. Predosing chemical stability of admixtures of propofol, ketamine, fentanyl, and remifentanil. Anesth Analg 2019; 129: e13-e15.

14. Ho CM, Tsou MY, Sun MS, Chu CC, Lee TY. The optimal effective concentration of lidocaine to reduce pain on injection of propofol. J Clin Anesth 1999; 11: 296-300.

15. Lonjaret L, Lairez O, Minville V, Geeraerts T. Optimal perioperative management of arterial blood pressure. Integr Blood Press Control 2014; 7: 49-59.

16. Melton JD, Heller MB, Kaplan R, Mohan-Klein K. Occult hypoxemia during aeromedical transport: Detection by pulse oximetry. Prehosp Disaster Med 1989; 4: 115-120.

17. Alsaif A, Alqahtani S, Alanazi F, Alrashed F, Almutairi A. Patient satisfaction and experience with anesthesia: A multicenter survey in Saudi population. Saudi J Anaesth 2018; 12: 304-310.

18. Atashkhoyi S, Negargar S, Hatami-Marandi P. Effects of the addition of low-dose ketamine to propofol-fentanyl anaesthesia during diagnostic gynaecological laparoscopy. Eur J Obstet Gynecol Reprod Biol 2013; 170: 247-250.
19. Hayakawa-Fujii Y, Takada M, Ohta S, Dohi S. Hemodynamic stability during induction of anesthesia and tracheal intubation with propofol plus fentanyl, ketamine, and fentanyl-ketamine. J Anesth 2001; 15: 191-196.

20. Tang YY, Lin XM, Huang W, Jiang XQ. Addition of low-dose ketamine to propofol-fentanyl sedation for gynecologic diagnostic laparoscopy: randomized controlled trial. J Minim Invasive Gynecol 2010; 17: 325-330.

21. Sinner B, Graf BM. Ketamine. Handb Exp Pharmacol 2008: 313-333.

22. Saadawy I, Ertok E, Boker A. Painless injection of propofol: pretreatment with ketamine vs thiopental, meperidine, and lidocaine. Middle East J Anaesthesiol 2007; 19: 631-644.

23. Baik HJ. Hormonal Responses during propofol-fentanylketamine anesthesia compared with propofol-fentanyl-N2O anesthesia. Korean J Anesthesiol 2003; 44: 452.

24. Erden IA, Pamuk AG, Akinci SB, Koseoglu A, Aypar U. Comparison of propofol-fentanyl with propofol-fentanylketamine combination in pediatric patients undergoing interventional radiology procedures. Paediatr Anaesth 2009; 19: 500-506.

25. Sakai T, Mi WD, Ebina T, Kudo T, Kudo M, Matsuki A. [Pharmacokinetics of propofol and ketamine during and after total intravenous anesthesia with propofol, fentanyl and ketamine for pediatric patients]. Masui 1998; 47: 277-280.

26. Sakai T, Mi WD, Komoda Y, Kudo T, Kudo M, Matsuki A. [Clinical indication of propofol for pediatric patients-pharmacokinetics of propofol and ketamine during and after total intravenous anesthesia with propofol, fentanyl and ketamine (PFK) in a neonate]. Masui 1998; 47: 314-317.

27. Childers CP, Maggard-Gibbons M. Understanding costs of care in the operating room. JAMA Surg 2018; 153: e176233.

28. Kakinohana M, Higa Y, Sasara T, Saikawa S, Miyata Y, Tomiyama H, et al. Addition of ketamine to propofol-fentanyl anaesthesia can reduce post-operative pain and epidural analgesic consumption in upper abdominal surgery. Acute Pain 2004; 5: 75-79.

29. WANG H, LIU F, AN W. Total intravenous anesthesia (Propofol, Ketamine, Fentanyl) in laparoscopy gynecolopy operation. Aerospace Medicine 2008: 3.

30. Park HS, Chung CJ, Chin YJ. Monitored anesthetic care (MAC) using propofol, ketamine, fentanyl, and ketorolac (PKFK) for minor surgery. Korean J Anesthesiol 2000; 39: 619-625.

31. Berning V, Laupheimer M, Nubling M, Heidegger T. Influence of quality of recovery on patient satisfaction with anaesthesia and surgery: a prospective observational cohort study. Anaesthesia 2017; 72: 1088-1096.

32. Onaka M, Akatsuka M, Takayama R, Mori H, Yamamoto H. [Electroencephalographic characteristics during maintenance and emergence from propofol-ketamine-fentanyl anesthesia]. Masui 2001; 50: 265-269.

33. Lee SH, Noh GJ, Chung BH. Monitoring of anesthetic depth with q-EEG (quantitative EEG) in TIVA (total intravenous anesthesia) and VIMA (volatile induction/maintenance anesthesia). Korean J Vet Res 2006; 46: 47-55. 